\title{
Methodology of the environmental efficiency assessment of spatial organization of rural areas
}

\author{
Oleksii Shkuratov $^{1 *}$, Viktoriia Chudovska ${ }^{2}$, Tetyana Kushniruk $^{3}$, Iryna Sotnikova ${ }^{2}$, and \\ Dmytro Sotnikov ${ }^{2}$ \\ ${ }^{1}$ Kyiv National University of Construction and Architecture, Rectorate, 03680 Kyiv, Ukraine \\ ${ }^{2}$ Kyiv National University of Construction and Architecture, Institute for Innovative Education, \\ 03680 Kyiv, Ukraine \\ ${ }^{3}$ State Agrarian and Engineering University in Podilia, 32316 Kamianets-Podilskyi, Ukraine
}

\begin{abstract}
The article features and substantiates the methodology of the environmental efficiency assessment of the spatial organization of rural areas. This methodology is based on a comprehensive analysis of key indicators to take reasoned decisions on land use arrangement and organization of agrolandscapes. At the same time, the research found that it is impossible to achieve sustainable land use without a comprehensive understanding of the situation on the spatial structure of territories, therefore, the initial stage of the model implementation is to analyze the current state and level of the research object. The methodology provides for taking into account the integral indicator of the spatial organization of rural areas, which is defined as the sum of normalized values of indicators (relative to their optimal level), with reference to the corresponding weighing coefficients. The advantage of the proposed approach is that it can determine the level of efficiency of optimization of the spatial structure of rural areas in the context of the region, which ensures the relative comparability of the calculated environmental indicators. Testing of the proposed assessment methodology on the example of Lviv region of Ukraine has proven its practical ability to optimize management decisions.
\end{abstract}

\section{Introduction}

Agricultural productivity depends on many natural factors, one of the most important being spatial nature of agroecosystems, which characterizes the environment and conditions of agricultural production, and also plays a decisive role in the development of rural areas. At the same time, an unbalanced land use structure and ecological imbalance of the land fund has significantly worsened the efficiency of land use and protection, as well as the natural self-restoring capacity of soil cover, and lead to depletion of the diversity of the flora and fauna of landscapes.

\footnotetext{
* Corresponding author: shkuratov.oleksii@gmail.com
} 
With the growing role of the agrolandscape organization of the territory and the expansion of its use as a tool for increasing the efficiency of agricultural production, attention to the theoretical issues of this phenomenon has also increased. However, some conceptual aspects of the spatial organization of rural areas still remain insufficiently developed. In particular, it is necessary to clarify the methodological foundations for assessing the environmental effectiveness of the spatial organization of rural areas. The need for an analytical assessment is beyond all question, since the data obtained as a result of such an assessment is essential while making appropriate management decisions that contribute to the choice of optimal strategic priorities and specific instrumental and methodological content within the land management mechanism.

It should be noted that interest in this issue is increasing as a result of the adoption of the Law of Ukraine "On Amendments to the Land Code of Ukraine and other legislative acts on land use planning" [1]. One of the main innovations of this Law is the unification of urban planning and land management documentation at the level of rural territorial entities into one document on spatial planning. However, it should also be noted that the mentioned document does not contain prerequisites for the ecological optimization of the structure of agricultural landscapes in rural areas. To ensure the combination of environmental components with spatial planning of territories, an appropriate regulatory and legal basis has not yet been determined. Domestic spatial planning of territories is a kind of continuation of strategic planning, that is where it is not aimed at a total study of territories taking into account environmental components in the process of developing appropriate documentation. In our opinion, to eliminate this deficiency the environmental aspects of environmental protection, based on the concept of sustainable development should be integrated into strategic planning.

\section{Literature Review}

The strategic goal of the development of any territory is to improve living standards of population, achieved through active investment activities, the creation of a new space, the placement of competitive industries with highly qualified jobs, comprehensive housing and social construction, and the like. Spatial structure of the territory and the system of land use are very important issues in this regard.

Today, the rational spatial organization of the territory as a whole is considered as a factor in increasing the efficiency of agricultural enterprises, therefore, an important issue is the formation of a system of organizational and economic support for this process in order to create optimal conditions for sustainable development of rural areas.

It should be noted that agricultural lands is a significant part of the system of spatial planning. Therefore, an integrated systematic approach to the study of various types of land use in rural areas will ensure the minimization of conflict situations, prepare effective options for their implementation and coordinate the socio-economic growth of rural areas with the protection and improvement of the quality of the environment. These issues are relevant the objectives of sustainable use of agricultural land. In general, the environmentally effective spatial organization of the territory consists in creating a stable ecological, economically and technologically sound optimization of agricultural production, the placement of productive forces and the social sphere where the efficiency will be ensured by reducing costs and reducing anthropogenic pressure on the environment. Thus, the main goal of substantiating the environmental efficiency of the spatial organization of rural territories is to identify the best option for streamlining the structure of agricultural landscapes and the location of productive forces and systematizing cost indicators that characterize the effectiveness of the project. 
In recent years, in scientific circles more and more attention has been paid to the study of the organization of the territory of agricultural enterprises on an agrolandscape basis, since agrolandscapes influence on agricultural lands, as the only component of nature. The agrolandscape approach is aimed at developing mechanisms for the formation of sustainable agrolandscapes under adverse natural phenomena and anthropogenic stress, as well as resource-saving technological approach to the processing of crops. At the same time, the greatest efficiency in applying this approach can be achieved if it is implemented within the framework of an integrated scientifically based system of agricultural nature management, which allows to optimize the set of environmental elements of the territorial structure of agrolandscapes and economic conditions of agrarian production [2, 3]. Therefore, in modern economic conditions, it is difficult to imagine balanced agricultural production without environmental and economic justification and rational spatial organization of land use.

In particular, J. Dissart and D. Vollet in their work investigated the influence of a number of agrolandscape factors of land use organization on the efficiency of agricultural activities [4]. The representative of the agroecological direction of economic research T. Harashchenko [5]systematized the spatial factors of agricultural production and analyzed their influence on the formation of land use. However, despite rather comprehensive study of these problems, the structural formation of land use and the organization of the territory of agrarian enterprises remains controversial. According to the method of V. Krivov [6], the ecological and economic effect of the organization of the territory of agricultural enterprises is equal to the abstract summer loss of soil fertility.

Among the scientific works that directly disclose the issues of assessing the environmental effectiveness of the spatial organization of the territory, it is worth recounting the article by $\mathrm{O}$. Baran [7] where he examines the methodology for assessing the effectiveness of the landscape organization of the territory of agricultural enterprises. Unlike established approaches, his methodology provides for a comprehensive analysis of the environmental, social and economic components of this process and covers a system of criteria and indicators that take into account the conditions of production and economic activity of a particular economy.

Other authors consider the possibility of using the concept of a neutral balance of land degradation as a basis for a methodology for the ecological efficiency assessment of spatial organization of agricultural territories. On the basis of the studies carried out, the authors distinguish four main types of models for the spatial organization of the territory, based on an expert assessment of their natural or natural-anthropogenic potential. The application of the proposed approach allows us to systematize the process of implementation of the practices of sustainable development of rural areas and to recommend approach for the systematic monitoring of land use in different regions [8].

The existing indicators to determine the stability of the territory, in our opinion, do not give a complete picture of the implementation of these measures, but generally evaluate certain environmental aspect. Therefore, despite the significant amount of theoretical and methodological research, a number of issues on assessing the environmental effectiveness of the spatial organization of rural territories are still poorly developed. The criteria and indicators, which most fully reflect the effectiveness of measures taken to optimize land in rural areas, have not been sufficiently studied.

\section{Material and methods}

Based on the results of the conducted studies and analytical generalization of existing methodological approaches to efficiency of spatial organization of rural areas assessment, we can state that today there are no modern developments that allow us to comprehensively 
assess its level using the appropriate criteria and indicators in accordance with the current conditions of management and specificity of the agrarian sector. Taking into account the specifics of agriculture, the formation of the methodological basis for assessing the efficiency of spatial organization of rural areas, in our opinion, should be carried out in several stages, namely: characterization of spatial factors; definition of integral index; the ranking of objects and zoning of the territory according to the level of environmental efficiency of spatial organization of rural areas. An important element of the informationanalytical component of the realization of methodology for assessing the efficiency of spatial organization of rural areas is a system of indicators that provide for the assessment and ranking of its species [8-11].

As J. Primdahl, L. Kristensen and A. Busck [12]in the process of diagnosing the ecological spatial structure of agricultural landscapes, the development of indicators and indices is designed to help in assessing the current state and choosing the required degree of intensity of environmental impact on the quality of land resources. In their opinion, the assessment of the spatial structure of agricultural landscapes should reflect the interaction and mutual influence of indicators according to the following criteria:

- indicators of environmental destructiveness, in fact, characterizes the consequences of non-fectin organization of the territory;

- indicators of the farm use of agroecosystems;

- indicators of ecological restoration, characterizing the state of implementation of measures for the rational organization of agricultural landscapes.

It should be noted that the formation of the list of indicators is based on the principle of representativeness (the most significant indicators affecting the level of spatial organization of territories are included), reliability (adequately reflect the state of the object being studied) and accessibility (the possibility and economic feasibility to obtain information data concerning the indicators). Based on the goals and objectives of the study, it seems appropriate to group the indicators of the spatial organization of territories within a certain integral index (Table 1) $[7,12,13]$. Moreover, this set can be expanded depending on the object of assessment (region, district, land use) and available information materials.

Table 1. The list of indicators of the environmental efficiency of spatial organization of rural areas, their weight and threshold values.

\begin{tabular}{|l|c|c|c|}
\hline \multicolumn{1}{|c|}{ Indicator } & $\begin{array}{c}\text { Indicator } \\
\text { thresholds }\end{array}$ & $\begin{array}{c}\text { Indicator } \\
\text { optimality } \\
\text { criterion }\end{array}$ & $\begin{array}{c}\text { Weight } \\
\text { coefficient, \% }\end{array}$ \\
\hline $\begin{array}{l}\text { Coefficient of ecological stability of the territory, } \\
\text { unit }\end{array}$ & 0,67 & Stimulant & 24 \\
\hline $\begin{array}{l}\text { Coefficient of ecological and technological } \\
\text { suitability, unit }\end{array}$ & 1,05 & Destimulator & 12 \\
\hline Coefficient of tension of relief, \% & 15 & Destimulator & 14 \\
\hline Coefficient of erosion rate, \% & 10 & Destimulator & 31 \\
\hline Environmental-agrochemical assessment, point & 100 & Stimulant & 11 \\
\hline Yield of cereals and legumes, centner/hectare & 50 & Stimulant & 8 \\
\hline
\end{tabular}

Source: author's elaboration.

In the process of studying integrated phenomena, where there are certain heterogeneous components that are not comparable with each other, the theory of index analysis is used. Using such an index method, it is possible to assess the impact of changes in certain factors, distributing them according to comparable and absolute deviations of the effective indicator. A necessary condition for calculating the indices is the ratio of current data on the actual situation in the territorial organization to their standard indicators [14]. In order to compare the different-quality and different-size indicators, it is proposed to interpret their 
values by standardisation. This method involves normalizing indicators to eliminate the difference in the dimensions of the parameters, that is, bringing them into dimensionless form with an interval from 0 to 1 ( 1 corresponds to the best (optimal) value of this indicator, and 0 is its worst (unacceptable) value). For this, the actual values of the indicators are compared with the threshold values of the corresponding indicator.

It should be noted that not all maximum values of actual indicators are optimal. Therefore, among the actual indicators reflecting certain indicator, stimulants (for which a high value of the indicator is optimal) and de-stimulants (for which a low value of the indicator is optimal) are distinguished. So, the value of the indicator is a stimulant defined as the ratio of the actual indicator to the optimal one. In this case, if the actual value of the indicator is higher or equal to the optimal one, it is set equal to 1. Accordingly, indicators of de-stimulators are determined by the ratio of the optimal value to the actual value, and if the value is below or equal to the optimal one, it takes the value of 1 [15]. So, the normalized values of indicators are calculated using the following formulas:

- for stimulants:

$$
\begin{aligned}
& X_{i}=1, \text { then } Y_{i} \geq Z_{i}, \\
& X_{i}=Y_{i} / Z_{i} \text {, then } Y_{i}<Z_{i},
\end{aligned}
$$

- for destimulators:

$$
\begin{aligned}
& X_{i}=1, \text { then } Y_{i} \leq Z_{i}, \\
& X_{i}=Z_{i} / Y_{i} \text {, then } Y_{i}>Z_{i},
\end{aligned}
$$

where: $Y_{i}-$ the factual value of the $i$-th indicator;

$Z_{i}$ - threshold (limiting) value of the $i$-th indicator;

$X_{i}$ - normalized value of the $i$-th indicator.

The determination of the optimal (limiting) values of indicators is carried out depending on their properties and using a number of methods. In particular, an analog method or a normative method is used to determine the reference value for certain indicators if the critical or optimal value is determined in regulatory legal acts (for example, maximum permissible concentration). In some cases, expert appraisal is conducted.

The next step is to determine an integral assessment of the environmental effectiveness of the spatial organization of rural areas, which is based on the calculation of an integral index that takes into account a set of indicators. When calculating the integral index for a certain period in the case of using indicators that have a frequency of more than one year (for example, an environmental-agrochemical assessment - once every five years), the latest available values of these indicators are used. To calculate the integral index of the environmental efficiency of the spatial organization of rural areas $\left(I_{e s}\right)$, the sum of the normalized values of the set of indicators included in them is determined, adjusted in accordance with their weight:

$$
I_{e s}=\sum_{i=1}^{n} x_{i} \times g x_{i},
$$

where: $g x_{i}-$ is the weighting factor of the $i$-th indicator;

$n-$ is the number of indicators used to calculate the integral index. 
Thus, the methodology, including a list of basic indicators, their normalization in accordance with certain threshold values, as well as the algorithm to calculate integral index, allow to assess the level of eco-efficiency of rural spatial organization.

\section{Results and discussion}

The environmental and economic effect of spatial organization of rural areas is determined by increasing crop yields, reducing the cost of processing crops, reducing or restoring soil fertility, protecting the soil from loss due to erosion, forest reclamation measures, and preventing damage from anthropogenic factors.

In order to test the proposed methodological approach, the integral index of the environmental efficiency of spatial organization of rural areas in the administrative districts of Lviv region of Ukraine was calculated. Average values are calculated over three year period, which is associated with fluctuations in crop yields, which is due to a significant discrepancy in natural climatic conditions and market conditions. The closer the value of the integral indicator to 1 , the higher the efficiency of spatial organization of rural areas and, vice versa.

In Table 2 shows the results obtained by our proposed methodological approach in the ranked order, according to the environmental efficiency of spatial organization of rural areas in the administrative districts of the Lviv region. At the same time, during the clusters formation, the correspondence of the obtained results to normal distribution was taken into account so that the areas grouping was conducted adequately and it was possible to carry out economic and statistical analysis methods.

Table 2. Environmental efficiency of spatial organization of rural areas of Lviv region of Ukraine, 2017-2019.

\begin{tabular}{|c|c|}
\hline District of Lviv region & Integral index $\left(I_{e s}\right)$ \\
\hline \multicolumn{2}{|c|}{ First group (from 0.76 to 1 ) } \\
\hline Stryiskyi & 0.85 \\
\hline Skolivskyi & 0.83 \\
\hline Mykolaivskyi & 0.77 \\
\hline Yavorivskyi & 0.76 \\
\hline \multicolumn{2}{|c|}{ Second group (from 0.51 to 0.75 ) } \\
\hline Buskyi & 0.74 \\
\hline Turkivskyi & 0.71 \\
\hline Kam ianka-Buzkyi & 0.66 \\
\hline Zolochivskyi & 0.63 \\
\hline Brodivskyi & 0.60 \\
\hline Zhovkivskyi & 0.54 \\
\hline \multicolumn{2}{|c|}{ Third group (from 0.26 to 0.50 ) } \\
\hline Starosambirskyi & 0.50 \\
\hline Drohobytskyi & 0.49 \\
\hline Zhydachivskyi & 0.46 \\
\hline Sokalskyi & 0.38 \\
\hline Radekhivskyi & 0.33 \\
\hline Sambirskyi & 0.30 \\
\hline Peremyshlianskyi & 0.27 \\
\hline \multicolumn{2}{|c|}{ Fourth group (from 0 to 0.25 ) } \\
\hline Pustomytivskyi & 0.24 \\
\hline Horodotskyi & 0.23 \\
\hline Mostyskyi & 0.20 \\
\hline
\end{tabular}

Source: calculated according to the analytical data. 
According to the integral index of the environmental efficiency of spatial organization of rural areas, the regional views as well as the regions rankings of Lviv region of Ukraine have been analyzed. As a result, we have identified four groups of clusters on the environmental efficiency of spatial organization of rural areas: the first group is the most efficient spatial organization of rural areas; the second is above-average level of efficiency in the region; the third is the below - average level of environmental efficiency in the region; the fourth group is inefficient spatial organization of rural areas.

\section{Conclusion}

Having tested the calculation method for integral indicator of the environmental efficiency assessment of the spatial organization of rural areas in the context of sustainable development of agriculture, we can talk about its applicability. Because it makes it possible for state authorities, as well as business entities and investors to take adequate management decisions and improve the efficiency of land use by agricultural producers.

The mandatory elements of practical implementation of the methodology for the environmental effectiveness assessment of the spatial organization of rural areas are: 1) a comprehensive analysis of the main indicators, taking into account spatial characteristics of territorial organization of rural areas; 2) method of rating these indicators in accordance with certain threshold values; 3 ) algorithm for calculating the integral index.

The integrated index of efficiency of the spatial organization of rural areas, following comprehensive assessment, makes it possible to assess this aggregate indicator across the regions of the country, which in the future will allow us to make motivated management decisions to prevent threats and risks in this area. The results of the research and analytical data on the level of the spatial organization of rural areas can be used in the development of regional strategies for the sustainable development of agriculture aiming to level out spatial differences in the form of a deviation between the actual and target state of agroecosystems.

In general, the organization of the territory of agricultural enterprises according to spatial parameters is required to reproduce the practical implementation of design decisions on land management, taking into account environmental standards that should be declared in schemes for the integrated development of rural areas.

\section{References}

1. Verkhovna Rada of Ukraine (2020). On amendments to the Land Code of Ukraine and other legislative acts of Ukraine regarding the land-use planning (Law of Ukraine № 711-IX from 17.06.2020). Official site Legislation of Ukraine. https://zakon.rada.gov.ua/laws/show/711-20\#Text

2. Soest, D., Stoop, J., \& Vyrastekova, J. (2016). Toward a delineation of the circumstances in which cooperation can be sustained in environmental and resource problems. Journal of Environmental Economics and Management, (77), 1-13. https://doi.org/10.1016/j.jeem.2015.12.004

3. Wood, S., Sebastian, K, \& Scherr, S. (2000). Pilot analysis of global ecosystems: agroecosystems. World Resources Institute.

4. Dissart, J., \& Vollet, D. (2011). Landscapes and territory-specific economic bases. Land Use Policy, 28 (1), 563-573. https://doi.org/10.1016/j.landusepol.2010.11.004

5. Harashchenko, T. (2013). Ecological-economic assessment of the impact of the agrolandscape organization of the territory on the efficiency of agricultural production. Balanced Nature Using, (2), 26-30. 
6. Krivov, V. N. (2007). Socio-economic problems of rural communities in the context of the transformation of agricultural land use and the formation of a land market in Ukraine. Land management and cadaster, (2), 9-13.

7. Baran, O. (2018). Methodical bases for assessing the effectiveness of the agrolandscape organization of the territory of agricultural enterprises. Balanced Nature Using, (3), 3339.

8. Zanten, B. et al. (2014). European agricultural landscapes, common agricultural policy and ecosystem services: a review. Agronomy for Sustainable Development, (34), 309325. https://doi.org/10.1007/s13593-013-0183-4

9. Shkuratov, A. I. (2017). Strategic Imperatives of Environmental Safety Management in the Agrarian Sector of Economy. Public Administration Issues, (4), 207-225.

10. Tretiak, A. (2012). Ecology of land use: theoretical and methodological bases of formation and administration. Hrin.

11. World Bank. (2006). Sustainable land management: challenges, opportunities, and trade-offs. World Bank. https://openknowledge.worldbank.org/handle/10986/7132

12. Primdahl, J., Kristensen, L., \& Busck, A. (2013). The farmer and landscape management: different roles, different policy approaches. Geography Compass, 7 (4), 300-314. https://doi.org/10.1111/gec3.12040

13. Hreshchuk, H. (2019). Efficiency of land management provision of sustainable land use of agricultural. Scientific Papers: Management, Economic Engineering in Agriculture \& Rural Development, 19(3). 275-280.

14. De Olde, E.M. et al. (2017). When experts disagree: the need to rethink indicator selection for assessing sustainability of agriculture. Environment, Development and Sustainability, 19(4), 1327-1342. https://doi.org/10.1007/s10668-016-9803-x

15. Kozmenko, O., Kuzmenko, A. (2014). Economic and mathematical methods and models (econometrics): a tutorial. University book. 